\title{
Clinical Observation of the Effect of Erbium-Doped Yttrium Aluminium Garnet Laser on the Treatment of Pit and Fissure in Children
}

\author{
YE. WU, W. LIU, YUMEI SONG ${ }^{1}$, YUFENG MEI ${ }^{1}$, JUAN LIN*AND XIN. WU* \\ Department of stomatology, Nanjing First Hospital, Nanjing Medical University, Nanjing 210006, China, ${ }^{1}$ Department of \\ Pediatric and Preventive Dentistry, Affiliated Hospital of Stomatology, Nanjing Medical University, Nanjing 210029
}

Wu et al.: Effect of Er:YAG Laser on the Treatment of Pit and Fissure in Children

\begin{abstract}
To apply erbium-doped yttrium aluminium garnet laser to the closure of young permanent teeth and pits, compare the total retention rate of sealants, and discuss whether erbium-doped yttrium aluminium garnet laser is suitable for clinical treatment in children. Sixty children with 6-9 y old and bilateral mandibular first molars with complicated sulcus were randomly divided into two groups: $A$ and $B$. The self-half control method was used: group A children's control side test teeth application of corundum The enamel was performed by enamel, acid etching, coating pit and fissure sealant, erbium-doped yttrium aluminium garnet laser enameloplasty was applied to the contralateral test teeth and pit and fissure sealant was applied; group B children's control side test teeth were treated with group A. The contralateral test teeth were treated with erbium-doped yttrium aluminium garnet laser enameloplasty, acid etching, and coating pit and fissure sealant. The children were scored for treatment after surgery, and regular follow-up was performed to observe the retention of the sealant. $63.3 \%$ of the children tested were willing to take the initiative to choose laser treatment. At the 3rd and 6th mo of follow-up, there was no significant difference in the total retention rate of the two groups of sealants $(p>0.05)$; at the 12th and 18th mos of followup, the total retention rate of the sealant materials: laser+etchant group>traditional bur. The difference between the needle group and the laser group was statistically significant $(p<0.05)$. Laser is a more acceptable treatment for children. Erbium-doped yttrium aluminium garnet laser is used in the formation of permanent enamel. It needs to be combined with acid etchant to enhance the retention of the sealant.
\end{abstract}

Key words: Erbium-doped yttrium aluminium garnet laser, pit and fissure seal, enamelplasty

Dental caries are common diseases in children and are frequently afflicted. It is now recognized that pit and fissure sealing technology can effectively prevent young permanent dentate sulcus ${ }^{[1]}$. The sulcus enamelplasty is one of the tooth surface treatment techniques, which can improve the retention rate of the sealant and enhance the anti-caries effect. The traditional mechanical method can form a pit and fissure quickly, but the noise and vibration during the treatment process can cause discomfort to the child, causing fear of the child and hindering the smooth progress of the treatment. At present, the concept of minimally invasive treatment is welcomed by doctors and patients. Among them, laser treatment has the advantages of precision, no vibration, no odor, no need for anesthesia ${ }^{[2]}$, and is favored by doctors and children. Erbium-doped yttrium aluminium garnet laser (Er:YAG laser) applied to children's dental hard tissue treatment mostly concentrated on isolated teeth. This study collected children's subjective feelings of laser treatment, and observed the clinical effect of Er:YAG laser applied to pit and fissure sealing treatment as follows: Sixty patients (120 first molars) were selected as outpatients. The age ranged from 6-9 y old, with an average age of $7.4 \pm 0.89$ y. The bilateral mandibular first molars were completely erupted without gingival coverage. Not bad, no filling, occlusal face pits are deep and complex. Er:YAG laser treatment instrument (Fotona M002$3 \mathrm{~A} / 4$, Fotonad d.d.), providing pulsed laser with a wavelength of $2940 \mathrm{~nm}$, beam transmission method is seven-section light guide arm, frequency range is 2-50 Hz, output pulse energy: 20-1500 mJ , maximum power: $20 \mathrm{~W}$. The mobile phone outputs a guide spot with a diameter of 2-7 $\mathrm{mm}$ and a wavelength of $650 \mathrm{~nm}$. The treatment device has built-in cooling water for easy movement. After signing the consent of the parents, we randomly divided the children into groups $\mathrm{A}$ and $\mathrm{B}$, 30 patients (60 teeth) in each group. The patients were 
treated with pit and fissure sealing with their own halfport control method. The test side was randomly assigned and the treatment sequence was random. The control sides of the two groups were treated with embolization using a emery bur, $37 \%$ phosphoric acid etched for $30 \mathrm{~s}$, and the resin-based pit and fissure sealant was applied after rinsing. Group A was irradiated with Er:YAG laser $(200 \mathrm{~mJ}, 20 \mathrm{~Hz})$, enamelplasty, directly coated with resin pit and fissure sealant, and group B was irradiated with Er:YAG laser for enamelplasty, then $37 \%$ phosphoric acid was etched for $30 \mathrm{~s}$ and the pit and fissure sealant was applied after rinsing. All treatments were performed by one tester. After each tooth is finished, let the child immediately score the operation noise and operation time, ask the child what kind of treatment and reason, and finally ask what kind of treatment is preferred if he is treated again. The questionnaire is as follows : , Name:, Gender:, Age:, Accompanying person:, date:. The first tooth: (answer 1 and 2 after the first tooth treatment is completed) 1. Please rate the noise during treatment: (1 point means no sound at all, 10 points means too noisy, unbearable) 1point, 2points, 3points, 4points, 5points , 6points , 7points, 8 points, 9 points, 10 points 2. Please rate the treatment time: ( 1 point means very fast, 10 points means too slow, can't stand it) 1point, 2points, 3points, 4points, 5points, 6points, 7points, 8points, 9 points, 10 points. The second tooth: (answer 2 and 4 after the second tooth treatment is completed) 3 . Please rate the noise during treatment: ( 1 point means no sound at all, 10 points means too noisy, unbearable) 1point, 2points, 3points, 4points, 5points, 6points, 7points, 8points, 9 points, 10 points 4 . Please rate the treatment time: (1 point means very fast, 10 points means too slow, can't stand it) 1point, 2points, 3points, 4points, 5points, 6points, 7points, 8points, 9 points, 10 points, (After all the operations are completed, answer questions 5, 6, and 7) 5. Compare the treatment of two teeth. Which method do you prefer? The first one. The second one can 6 . Can you tell me why I like it? 7. If you come to treat your teeth next time, which method do you prefer to choose? The first one. The second one can The child's parents were reviewed at 3, 6, 12 and 18 mos after treatment to see if the pit and fissure sealant was completely retained. The review criteria for blocking agents are divided into complete retention, partial shedding, and total shedding ${ }^{[3]}$. Completely reserved: all pit and groove gap sealant retention is good, no shedding; partial shedding: part of the pit and fissure sealant shedding; all shedding: the sealant in the pit and groove all fall off. Total retention rate $=($ completely retained teeth + partially retained teeth)/number of follow-up teeth $\times 100 \%$. Statistical analysis was performed using SPSS19.0 statistical software. The chi-square test was used to compare the retention rate of the blocking agent. The difference of $\mathrm{p}<0.05$ was statistically significant. The children who participated in the trial were able to complete the treatment. $50(83.3 \%)$ children thought that the laser treatment was less noisy, and $10(16.7 \%)$ children felt that the two were similar. The children in group A thought that the treatment time was close to both sides, $28(93.3 \%)$ children were willing to take the initiative to choose laser treatment, 2 cases $(6.67 \%)$ children had no tendency; group B (19.3\%) children considered laser treatment The time was too long, and 7 of the children in the test were interrupted because of the long time, and they closed their mouths. Only 10 (33.3\%) children were willing to take the initiative to choose laser treatment, and $13(43.3 \%)$ children were not inclined, $7(23.3 \%)$ Children prefer to choose traditional diamond bur treatment. No patients were lost to followup at 3 mos after surgery, and the follow-up rate was $100 \%$. A total of 3 children were lost to follow-up at 6 mo after surgery, and the follow-up rate was $95 \%$. A total of 9 children were lost to follow-up at 12 mo after surgery, and the follow-up rate was $85 \%$. A total of 13 children were lost to follow-up at 18 mo postoperatively, with a follow-up rate of $78.3 \%$. The retention rates of the blocking agents in groups $\mathrm{A}$ and $\mathrm{B}$ at 3, 6, 12 and 18 mos after operation are shown in Tables 1 and 2. The total retention rate of the blocking agents in each group was close at 3 and 6 mos after operation, and the difference was not statistically

TABLE 1: GROUP A BLOCKING AGENT RETENTION RATE

\begin{tabular}{|c|c|c|c|c|c|c|c|c|}
\hline & \multicolumn{2}{|c|}{$3 \mathrm{mo}$} & \multicolumn{2}{|c|}{$6 \mathrm{mo}$} & \multicolumn{2}{|c|}{$12 \mathrm{mo}$} & \multicolumn{2}{|c|}{$18 \mathrm{mo}$} \\
\hline & laser & needle & laser & needle & laser & needle & laser & needle \\
\hline $\begin{array}{l}\text { Completely } \\
\text { reserved+partially detached }\end{array}$ & 30 & 30 & 28 & 29 & 22 & 24 & 17 & 21 \\
\hline Completely shedding & 0 & 0 & 1 & 0 & 3 & 1 & 7 & 3 \\
\hline Lost & 0 & 0 & 1 & 1 & 5 & 5 & 6 & 6 \\
\hline Total retention rate & $100 \%$ & $100 \%$ & $96.6 \%$ & $100 \%$ & $88 \% *$ & $96 \%$ & $70.8 \% *$ & $87.5 \%$ \\
\hline
\end{tabular}

* Total retention rate bur needle group >laser group, $\mathrm{p}<0.05$. 
TABLE 2: GROUP B BLOCKING AGENT RETENTION RATE

\begin{tabular}{|c|c|c|c|c|c|c|c|c|}
\hline & \multicolumn{2}{|c|}{$3 \mathrm{mo}$} & \multicolumn{2}{|c|}{$6 \mathrm{mos}$} & \multicolumn{2}{|c|}{$12 \mathrm{mos}$} & \multicolumn{2}{|c|}{$18 \mathrm{mos}$} \\
\hline & $\begin{array}{l}\text { Laser+acid } \\
\text { etching }\end{array}$ & needle & $\begin{array}{l}\text { Laser+acid } \\
\text { etching }\end{array}$ & needle & $\begin{array}{l}\text { Laser+acid } \\
\text { etching }\end{array}$ & needle & $\begin{array}{l}\text { Laser+acid } \\
\text { etching }\end{array}$ & needle \\
\hline $\begin{array}{l}\text { Completely } \\
\text { reserved+partially } \\
\text { detached }\end{array}$ & 30 & 30 & 28 & 28 & 26 & 25 & 22 & 20 \\
\hline Completely shedding & 0 & 0 & 0 & 0 & 0 & 1 & 1 & 3 \\
\hline Lost & 0 & 0 & 2 & 2 & 4 & 4 & 7 & 7 \\
\hline Total retention rate & $100 \%$ & $100 \%$ & $100 \%$ & $100 \%$ & $100 \% *$ & $96.2 \%$ & $95.7 \% *$ & $87.0 \%$ \\
\hline
\end{tabular}

significant ( $>00.05$ ). At 12 and 18 mo follow-up, the total retention of the blocking agent: laser+etchant group $>$ traditional bur needle group $>$ laser group, the difference was statistically significant $(\mathrm{p}<0.05)$. Pit and fissure closure as an effective method to prevent sulcus in young permanent molars has been confirmed by many studies and is widely used ${ }^{[4]}$. Effective tooth surface treatment can increase the permeability of the sealant and facilitate the retention of the pit and fissure sealant. The traditional method of tooth surface treatment is to clean the groove surface with a cup brush. This method can effectively remove the plaque and food debris in the cusp slope and the shallow pit. However, due to the complicated shape of the pit and groove, the traditional method cannot Clearing plaque and food debris deep in the pit, it is difficult for the etchant and sealant to enter the stenosis of the pit and fissure $^{[5]}$. The enameloplasty sealant technique (EST) is a method of fissure closure after mechanical expansion of the orbital fossa. Experiments have shown that changing the shape of the pit and fissure is conducive to clearing the plaque and debris in the deep sulcus of the sulcus, so that the etchant and the sealant can smoothly enter the pit. At the same time, the high-mineral layer with no structure on the enamel surface is removed, which can enhance the acid etching effect, improve the adhesion between the resin and the enamel, and reduce the occurrence of microleakage at the edge of the sealant. However, after De Graene and other experiments, it is believed that the diamond grinding wheel has less tooth tissue and high efficiency, but it is easy to remove excessive tooth tissue ${ }^{[6]}$. Er:YAG laser is a hydrodynamic biological laser system with a wavelength of $2940 \mathrm{~nm}$, which is located near the absorption peak of infrared molecules of water molecules and hydroxyapatite. Water molecules or hydroxyphosphorus in teeth the limestone absorbs the laser, the temperature rises rapidly, vaporizes, and a "micro-explosion" occurs inside the tissue to achieve the effect of cutting the tooth structure. Moreover, the higher the moisture content of the tissue, the smaller the energy required for cutting. By controlling the output power of the Er:YAG laser, precise cutting can be performed on the target tissue. The Er:YAG laser is a medium-infrared laser with poor penetrability and can penetrate only about $0.01 \mathrm{~mm}$ of tooth tissue. This performance ensures that Er:YAG laser treatment is minimally invasive ${ }^{[7]}$. At present, there are many clinical applications of Er:YAG laser, such as: decommissioning cave, squat treatment, preventive filling, pulp cutting, soft tissue minor surgery, etc ${ }^{[8]}$. The enamel irradiated by Er:YAG laser can be seen under the scanning electron microscope: the illuminating area has a scaly appearance, the enamel structure is clear, and no smear layer is seen; after the irradiation, the enamel surface structure is more uniform, and the enamel structure is observed. The core is selectively removed and the interstitial matrix is almost completely retained ${ }^{[9]}$. Such a structure facilitates the penetration of the resin of the sealant into the glaze column and increases the retention of the sealant. The Er:YAG laser is applied to the pit and fissure closure. In theory, the decontamination, cleaning and finishing are completed in one step, and the enamel resistance after laser treatment is increased ${ }^{[10]}$. However, Qiao Liyan, Liu Jingming and other isolated tooth studies showed that if the sealant was directly applied after Er:YAG laser treatment, the edge microleakage was obvious ${ }^{[11]}$; their other group of isolated teeth experiments confirmed the use of Er:YAG After laser treatment combined with the use of acid etchants, the retention effect of the sealant is the same as that of the conventional method, and there is no significant difference in the degree ofmicroleakage. Therefore, in order to improve the adhesion, scholars suggest that laser treatment cannot replace the acid etching method, and laser treatment of enamel and dentin is still needed after laser treatment ${ }^{[8]}$. This clinical trial found that the retention rate of the blocking agents in each group was close within 6 mo after surgery, and there was no statistical difference. With the prolongation of observation time, the total retention rate of the sealant material at 12 and 18 mo after surgery: laser+etchant 
group $>$ traditional bur needle group $>$ laser group, the difference was statistically significant $(p<0.05)$. In order to increase the retention of the sealant, the laser treatment with the acid etchant is the best. This test is for school-age children, most of them can actively cooperate with the treatment, a few have vomiting reaction, no crying during treatment. Laser treatment is far superior to traditional methods in terms of noise, but it takes a long time to operate, and children under the age cannot adhere to it. Seven children required to discontinue the treatment process in this trial were all under $7.5 \mathrm{y}$ of age. Zhang Zhu and other studies also found that laser treatment time is longer, some patients cannot accept it, it is recommended that in the hard tissue treatment of the tooth, turbine and laser can be used together to improve work efficiency ${ }^{[12]}$. This clinical trial is consistent with the isolated tooth test. It is observed that the Er:YAG laser combined with the etchant can really improve the retention rate of the pit and fissure sealant. It is necessary to consider how to shorten the operation time and let more children receive treatment happily.

\section{Author's contributions:}

JUAN LIN and XIN WU conceived and designed the experiments are considered as co-corresponding authors; YUMEI SONG and YUFENG MEI performed the experiments; YE WU and WEI LIU analyzed the data and wrote the paper and contributed equally to this work.

\section{Acknowledgements:}

This work was supported by the Preventive Medicine Research Project of the Jiangsu Provincial Health and Family Planning Commission (No. Y2015051).

\section{Conflict of interest}

The authors report no conflicts of interest.

\section{REFERENCES}

1. Bian JY. Preventive Stomatology. 4th edition, Beijing: People's Medical Publishing House 2005:122-45.

2. Wang X J. Minimally invasive technique for diagnosis and treatment of oral diseases in children. Chin J Pract Stomatol 2012;5:449-53.

3. Peng SM, Zhao W, Lin JC. Evaluation of the effect of selfetching adhesive on the sealing of permanent sockets and pits. Shang J Stomatol 2006;15:571-4.

4. Liu W, Cao L, Zhang YG. In vitro study of the effects of different pit and fissure treatment methods on microleakage and marginal microleakage of pit and fissure sealants. Stomatology 2010;30:420-2.

5. Ling ZY, Ding W, Lu CH. Effects of different enamel treatment methods on microleakage of pit and fissure sealant. J Health Sci 2012;44:323-6.

6. De-Graene GP, Martens C, Dermaut R. The invasive pit-andfissure sealing technique in pediatric dentistry: an SEM study of preventive restoration. ASDC J Dent Child 1988;55:34-42.

7. Kilinc E, Roshkind DM, Antonson SA. Thermal safety of $\mathrm{Er}$ : YAG and $\mathrm{Er}, \mathrm{Cr}$ : YSGG lasers in hard tissue removal. Photomed Laser Surg 2009;27:565-70.

8. Zhang S. Research and application of Er:YAG laser in children's oral cavity. Chin J Pract Stomatol 2015;8:209-13.

9. Sasaki LH, Lobo PD, Moriyama Y. Tensile bond strength and SEM analysis of enamel etched with Er: YAG laser and phosphoric acid: A comparative study in vitro. Braz Dent J 2008;19:57-61.

10. Mollica FB, Camargo FP, Zamboni SC. Pulpal temperature increase with high-speed handpiece, Er:YAG laser and ultrasound tips. J Appl Oral Sci 2008;16:209-13.

11. Qiao LY, Liu JM, Wang J. Effect of Er:YAG laser preparation of cavity on microleakage of resin filling. J Modern Stomatol 2009;23:179-81.

12. Zhang Z, Chen T, Ge LH. Evaluation of the effect of Er:YAG laser in the treatment of dental caries in children. J Health Sci 2013;45:87-91.

This is an open access article distributed under the terms of the Creative Commons Attribution-NonCommercial-ShareAlike 3.0 License, which allows others to remix, tweak, and build upon the work non-commercially, as long as the author is credited and the new creations are licensed under the identical terms

This article was originally published in a special issue, "Trends in Therapeutic Management of Various Clinical Conditions II" Indian J Pharm Sci 2021:83(2)Spl issue;106-109 